\title{
A SIGNIFICAÇÃO DA INFÂNCIA EM DOCUMENTOS DO MST ${ }^{1}$
}

\section{EI Significado de la Infancia en los Documentos del MST}

Márcia Mara Ramos

Educadora Popular do Movimento dos Trabalhadores Rurais Sem Terra-MST. marciapterra@gmail.com

Artigo recebido em 11/12/2013 e aceito para publicação em 22/12/2013

DOI: 10.12957/tamoios.2013.8163

RESUMO O presente artigo tem por objetivo analisar, a significação da infância e da criança em documentos do MST e sistematizar um conjunto de documentos que auxiliam na compreensão do processo de construção do sujeito coletivo Sem Terrinha. Defende-se que buscar compreender a significação da infância Sem Terra para o MST pode nos permitir apontar para a inclusão da categoria infância e do sujeito criança no debate acerca dos movimentos contra hegemônicos ao sistema capitalista, mesmo que esses movimentos estejam prioritariamente protagonizados pelos sujeitos adultos de seus grupos sociais. O método de pesquisa consistiu no levantamento de documentos sobre a infância que o MST produziu nos 29 anos de luta pela terra e análise da presença da criança no processo de luta social.

Palavras chaves: Significação; Infância Sem Terra; Coletividade; Ciranda Infantil

RESUMEN El presente artículo, tiene por objetivo analizar el significado de la infancia y el niño en documentos del MST y sistematizar un conjunto de documentos que ayuda en la comprensión del proceso de construcción del sujeto colectivo Sem Terrinha. Se defiende que buscar comprender el significado de la infancia sin tierra del MST nos puede permitir direccionar para inclusión la categoría infancia y del sujeto niño en el debate acerca de movimientos contra hegemónicos al sistema capitalista, aunque esos movimientos son prioritariamente protagonizados por sujetos adultos de su grupos sociales. El método de investigación consistió en el levantamiento de documentos sobre la infancia que el MST ha producido en los 29 años de lucha por la tierra y análisis de la presencia del niño en el proceso de lucha social.

Palabras llaves: Significado; Infancia Sin Tierra; Colectividad; Ciranda Infantil 


\section{INTRODUÇÃO}

O presente artigo tem como objetivo analisar, as ações realizadas com as crianças Sem Terra, a significação da infância em documentos e assim também contribuir na compreensão do papel da criança no processo de luta social.

No primeiro momento analisamos a infância nos acampamentos e assentamentos do MST, buscando nos processos históricos o papel que a criança cumpriu no desenvolvimento do capitalismo, onde a realidade das crianças, em particular das crianças pobres, esteve, atrelada ao trabalho infantil, que atualmente ainda persiste e configura-se de diferentes formas. Nesse contexto a criança Sem Terra vive em sua realidade a ocupação da terra, um lugar de conflito, de luta e de projeto. Essa realidade social em que a criança Sem Terrinha está inserida tem proporcionado a sua significação enquanto sujeito coletivo.

No segundo momento, analisamos A infância nos documentos do MST, que estão categorizados da seguinte forma; a) documentos sobre a infância: são documentos de concepção e relato de experiências; b) documentos para as crianças: materiais cujo objetivo é o estabelecimento de um diálogo com as crianças, ou seja, destinado diretamente a elas. c) documentos para e com as crianças: materiais em diferentes linguagens produzidos em atividades que contaram com a participação de crianças do MST.

Os documentos selecionados são produções coletivas que o MST nesses 29 anos acumulou, tendo como principal intelectual da infância o Setor de Educação.

\section{A infância nos acampamentos e assentamentos do MST;}

A infância diz respeito a um momento de vida de sujeitos em alteridade com outros segmentos etários, ou seja, um tempo de vida com determinadas especificidades. Essas especificidades caracterizam agendas e pautas diferenciadas para as crianças, entendidas nesta pesquisa como sujeitos concretos que vivem determinadas infância, numa materialidade que é produto de relações sociais abrangentes.

Isso significa dizer que a infância e as possibilidades de ser criança modificam-se conforme as relações sociais, políticas e econômicas. Esta concepção de infância que sustenta esse trabalho é compartilhada com Kramer (1995), que entende a infância e a "questão da criança" em consideração ao processo histórico em que as mesmas se inserem:

A análise das modificações do sentimento devotado à infância é feita à luz das mudanças ocorridas nas formas de organização da sociedade, o que contribui para uma maior compreensão da "questão da criança" no presente, não mais estudada como um problema em si, mas compreendida segundo uma expectativa do contexto histórico em que está inserida. (KRAMER, 1995 p. 17)

Para Lombardi (2010), a criança nos diferentes modos de produção foi inserida no processo de exploração do trabalho. Mas com a Revolução Industrial, marcada por uma transição na técnica do trabalho artesanal para o industrial a qual intensificou o ritmo do trabalho e do uso da mão de obra feminina e infantil, ocorreu "a difusão em larga escala do trabalho infantil" transformando não só o trabalho, mas também as relações sociais e mentalidades, incorporando a criança no processo da exploração do trabalho. 
No Brasil, historicamente, a criança desde a colonização trabalha. A infância foi, portanto, incorporada ao mundo do trabalho no contexto da colonização, o que decorre daí a utilização das mesmas formas de exploração da mão de obra adulta. Da mesma forma, a condição de pobre, de origem africana ou européia, caracteriza as condições de sobrevivência das crianças como bastantes perversas. Segundo Priori, (2008, p.12), dentre os escravos que desembarcavam no mercado do Valongo, no Rio de Janeiro, no século XIX, 4\% eram crianças. E essas crianças, com corpo de adulto e sem infância, foram sendo direcionadas para o trabalho escravo a serviço dos senhores. Priori afirma que,

a partir dos 4 anos, muitas delas já trabalhavam com os pais ou sozinhas, pois perder os genitores era coisa comum. Aos 12 anos o valor de mercado dessa criança já tinha dobrado. E por que? Pois considerava-se que seu adestramento já estava concluído e nas listas dos inventários já apareciam com sua designação estabelecida: Chico "roça", João "pastor", Ana, "mucama", transformados em pequenas e precoces máquinas de trabalho. (Priori, 2008, p.12).

Elas deixam o mundo infantil para assumir uma vida adulta e, mesmo com a abolição da escravidão, elas continuam trabalhando nas fazendas de cana e morando nas senzalas. Assim, na formação do Brasil, as crianças formaram uma parcela grande no projeto de colonização incorporadas como parte do desenvolvimento e da construção social, cultural e política de um país em "descobrimento". Evidentemente, as possibilidades de vivência da infância não foram as mesmas para as crianças de diferentes classes e grupos sociais.

A realidade das crianças no país, em particular das crianças pobres, esteve, portanto, atrelada ao trabalho infantil que, embora nitidamente mais evidente nos tempos do Brasil colônia, atualmente ainda persiste e configura-se de diferentes formas. Ou seja, a realidade de determinadas crianças, verificada há séculos, perdura sob o capitalismo e sob as diferentes formas de seu desenvolvimento.

A existência do trabalho infantil, nos dias atuais, em que pese avanços nessa questão, pauta com mais visibilidade a violação de direitos da criança no Brasil. A emergência de uma área de estudos sobre a infância e a aprovação de algumas leis remete à compreensão social da infância numa perspectiva da criança como sujeito de direitos. Dentre a legislação, citamos a Lei Federal n ${ }^{\circ} 8.069$, o Estatuto da Criança e do Adolescente - ECA (1990) e a Convenção Internacional sobre os Direitos da Criança, aprovada na Assembléia Geral das Nações Unidas (1989). As várias atividades laborais que, em nome da sobrevivência das famílias ou da necessidade da acumulação do capital, forçam a criança assumir a responsabilidade de contribuir (seja em casa no cuidado dos irmãos para que os pais possam trabalhar, seja no trabalho agrícola, em especial nos canaviais que exige um trabalho exaustivo), retirando da criança o direito de ter uma educação com qualidade.

O grande desafio colocado é buscarmos compreender a criança no processo da sua formação inserida nas relações sociais que a constituem. Sob o capitalismo, os seres humanos, dentre os quais as crianças, têm sua infância roubada de diferentes formas: pelo excesso de exigências, de consumo, da violência, do trabalho, entre outras.

Tomamos como pressuposto deste artigo, condizente com as reflexões do marxismo, que a emancipação da humanidade, e, consequentemente da infância, pressupõe a superação das relações sociais atuais. Por isso, essa discussão também se vincula à construção de um projeto de sociedade numa perspectiva coletiva e emancipatória que considere também os aspectos relativos às relações 
geracionais e etárias, que possibilite crianças, jovens, adultos e idosos a terem a possibilidade de se desenvolver plenamente.

Pensar a infância e a criança no MST significa, portanto, mover-se nesse contexto histórico, reconhecendo as determinações e a concretude dessa infância e dessa criança.

A criança no MST está presente desde a sua origem. Como membro de uma família, acompanhava seus pais desde as primeiras ocupações. $\mathrm{O}$ reconhecimento dessa relação conjunta exige que a investigação sobre a criança tome como ponto de partida sua materialidade, neste caso, requer a compreensão das relações sociais de seu contexto de luta pela terra e vinculado a um Movimento que tem como estratégia política a transformação radical da sociedade. É necessário, portanto, estabelecer nexos e relações que contemplem tanto a criança como o grupo social (o Movimento, classe trabalhadora) ao qual pertence, considerando que a criança não está separada da vida material e, portanto, ela é parte constitutiva da construção histórica do Movimento.

A criança e a infância no MST fazem parte, portanto, desse processo de luta, nesse contexto histórico. Dialogar com a possibilidade da construção de outro projeto social, pautado por outra sociabilidade, tem sido colocado por este Movimento como objetivo fundamental. Nessa luta, parece evidenciar-se que essa nova sociabilidade inclui também novas formas de relação entre as gerações. Contudo, cabe nos perguntarmos sobre o lugar dessa criança nessa proposta. Desta forma, nossa problemática central busca responder: Qual a significação da infância no MST? Desta questão se desdobram outras: Como é pensada e qual a contribuição da criança nas diferentes atividades e documentos do MST? Que referência de coletividade o movimento vem praticando no processo de trabalho com as crianças? E qual é a contribuição desses processos para a formação da criança?

Compreender a infância no/do MST que está nos acampamentos e assentamentos, nas marchas, nas ocupações, nos cursos, reuniões e encontros diversos é dialogar com um processo educativo fora da escola, não institucionalizado pelo poder público, marcado principalmente pelo conceito de coletividade, numa compreensão de que o lugar educativo da criança não se restringe somente à escola, porém não a desconsidera, ou seja, considera educativo todos os espaços ocupados pelas crianças, sendo que a depender da intencionalidade e ação dos sujeitos envolvidos pode contribuir para reproduzir ou questionar a sociedade em questão.

A vivência dessa coletividade, muitas vezes, é circunscrita pela ausência do trabalho, da moradia, de educação e saúde. Ao mesmo tempo, essa realidade proporciona um ambiente onde as pessoas não se conformam com essa realidade e lutam para mudá-la, ocupando terras, lutando pelo acesso à escola, às políticas públicas de saúde e educação. Desta forma, a luta coletiva se realiza a partir de uma necessidade comum.

O MST, inspirado em outras lutas e pedagogias socialistas, procura aprofundar os estudos para o trabalho com a infância. Dentre estas inspirações destacam-se os processos revolucionários cubano e soviético como referenciais, principalmente, no que tange ao próprio conceito de coletividade e de autonomia, entendida como a auto-organização das crianças, tal como presente nas reflexões de Pistrak,

Se a auto-organização das crianças na escola soviética não se basear na existência do coletivo infantil, será uma disposição abortiva. Mas, perguntará o leitor, qual é a escola "onde não há coletivo Infantil". Isso é verdadeiro, se considerar o coletivo como reunião acidental de uma certa quantidade de crianças num mesmo lugar visando à formação, isto é, visando a algo que se refere apenas ao aspecto exterior de suas preocupações, um objetivo que não exprime ainda o interesse infantil. Mas uma certa 
quantidade de crianças, um simples agrupamento quantitativo, uma reunião acidental, não formam ainda um coletivo. (PISTRAK, 2000, p.176-177)

Neste sentido, é importante compreender que pensar sobre as crianças é uma demanda apresentada pelas próprias famílias que buscam, na inserção no movimento popular, novas condições de vida, um melhor "futuro" para os filhos. No acampamento, por exemplo, por mais que as condições sejam precárias, visualiza-se um horizonte de esperança em ter a terra, a moradia, a educação e saúde, etc, conquistas que ficarão como "herança" para seus filhos.

Há de se reconhecer que, para um movimento campesino que carrega em suas tradições uma cultura patriarcal, a participação da mulher e da criança na luta é limitada. A tendência é sempre a presença do homem nos diferentes espaços de atuação, bem como nas tomadas de decisões. Na pesquisa de Martins, relatada em sua obra: O Massacre dos inocentes (1991), ele descreve como as crianças, as mulheres, os velhos, os agregados, ou dependentes, que vivem de favor no campo, são um público estranho e que permanece sempre em silêncio.

Desta forma, a busca por compreender o processo e o projeto em que está inserida a criança no contexto de luta pela terra, e o MST como lugar e significação da infância Sem Terra, são elementos fundamentais para o processo da pesquisa, e busca romper com o silêncio e a estranheza apontada por Martins.

Sempre me chamou atenção que nessas horas estivesse presente, de pé ou de cócoras pelos cantos, grupos numerosos e atentos de um público que, aparentemente, não se sentia no direito de falar e perguntar. Refiro-me às crianças. Um grupo que não fala, mas ouve muito. Decidi dirigir-me também a elas na minha pesquisa sobre a luta pela terra. (MARTINS, 1991, p. 56).

Convém registrar que o MST, como parte da sociedade, sofre influência da história e de concepções de diferentes naturezas. Trata-se, portanto, de um Movimento não necessariamente homogêneo, cujas contradições estão presentes nos sujeitos que o constituem e também em suas produções. O MST, sendo uma organização política, preconiza a organização de homens e mulheres que buscam mais do que um pedaço de chão; pretende a construção de uma nova forma de vida para si e para sua família, fazendo da presença da criança uma constância nas atividades do Movimento. Entendendo que a criança está no processo da luta, nos questionamos: seria ela vista como sujeito? Ou concebida como um ser em processo, sendo necessário trabalhá-la para vir a ser sujeito?

Se considerarmos o que afirma o MST $(2008$, p.13) "que o lugar da infância do MST é o próprio movimento", esta é uma tarefa de toda a organização e não apenas de um setor. Como isso aparece nas suas elaborações coletivas, como cadernos, cartilhas, relatórios, orientações políticas e linhas de ações? Que significações sobre a criança e infância aparecem? Como falam e o que falam das crianças? Como se pauta a participação das crianças nesses documentos?

São algumas das questões que norteiam esse trabalho, no sentido de compreender o sentido, as contradições, limites e possibilidades de um movimento camponês que luta pela terra e que considera as relações etárias, em particular, no trabalho desenvolvido com as crianças.

\section{A INFÂNCIA NOS DOCUMENTOS ${ }^{2}$ DO MST}




\section{HISTÓRIA E CONTEXTO DE PRODUÇÃO DOS MATERIAIS: APONTAMENTOS DAS PRINCIPAIS AÇÕES DO MST EM RELAÇÃO À INFÂNCIA}

Neste artigo analisamos a problemática da infância no MST a partir de documentos e produção coletiva. O conjunto dos materiais levantados foi produzido em diferentes momentos históricos do MST e em práticas construídas ao longo de sua existência. Conhecer essas principais ações é fundamental para a compreensão do contexto em que se situam os documentos que registram e, ao mesmo tempo, impulsionam a construção das práticas e de novas significações sobre a infância.

A particularidade do tema da infância e da criança ganha espaço no interior do Movimento e pode ser acompanhada pelas experiências singulares pensadas para suas crianças e, posteriormente, com elas.

As atividades propostas para as crianças são diversas. Destaco aqui uma atividade recente que teve impacto nas discussões atuais sobre a infância, mas expressou também uma síntese do que já vinha sendo debatido no Movimento. No Caderno intitulado "Escola Itinerante Paulo Freire no $5^{\circ}$ Congresso do MST" (s/data), da Coleção Fazendo Escola, encontramos uma sistematização desta experiência, realizada no ano de 2007, em Brasília. Um dos trechos permite-nos visualizar a proposta de trabalho desenvolvida com as crianças no Movimento, naquela oportunidade:

[...] durante toda manhã, foi anunciada a chegada de alguém muito especial. Realmente muito especial! Muitos chegaram a pensar em autoridades importantes, no presidente, governadores ou na filha do Che. Mas não. Enfim a entrada dos sujeitos esperados! As crianças Sem Terra tomaram conta do Ginásio Nilson Nelson com pernas de pau, palhaços, balões, bolas, bonecas e toda a infra-estrutura brincante. Eram tantas crianças em marchas que não paravam de entrar. A música trazia a alegria de estar ali, dançando e cantando. E numa grande ciranda de emoção, lágrimas, sonho e luta, os Sem Terrinha ocuparam o "lugar da Infância Sem Terra" reafirmando naquele momento o compromisso do conjunto do MST. (MST, s/data, p.33-34)

Esse foi um dos espaços mais expressivos nacionalmente, ocupados pelos Sem Terrinha. Pode-se dizer que se fortaleceu, neste momento histórico, porque foi fruto de outras experiências e do acúmulo de discussões de ações sobre a infância no MST, como a Marcha Nacional "Por Reforma Agrária, Emprego e Justiça Social”, realizada em 2005.

Na avaliação da mobilização de 2005, realizada por sua coordenação, atenção particular foi dada a respeito de como as crianças estavam sendo pensadas e cuidadas nos espaços do MST. Um dos trechos diz o seguinte: "os educadores/as observavam a situação em que as crianças chegavam. As noites e manhãs eram muito frias e muitas crianças vinham descalças e sem agasalhos. Muitas pela situação social, desnutridas e com sinas de descuido da própria família”. (MST s/data, p.11). Com essa reflexão, o debate foi pautado em nível nacional, no Encontro da Coordenação Nacional do MST, na cidade de Goiânia, em 2007. Essa foi uma auto provocação para uma avaliação mais profunda do lugar da infância no Movimento.

No histórico dos marcos da infância no MST, dentre as diferentes ações, podemos encontrar três grandes referências ao trabalho não institucionalizado pelo poder público, com as crianças Sem Terra: o Encontro dos Sem Terrinha; a Ciranda Infantil e as produções de comunicação e cultura. Abaixo, descrevo brevemente cada uma delas. Grande parte destas ações foi acompanhada de processos de documentação, várias dessas, resultaram em publicações. 


\section{ENCONTRO DOS SEM TERRINHA}

A proposta de realização dos Encontros dos Sem Terrinha nasce como um contraponto à visão mercadológica da data de comemoração do dia da criança no Brasil. No Movimento, o mês da criança é comemorado misturando festa, brincadeiras, estudos e luta. Realizados desde 1994, inicialmente foram chamados de Congresso Infanto-Juvenil. Em 1997, passam a ser chamados de Encontros dos Sem Terrinha. Estes possuem caráter regional e/ou estadual e sempre procuram manter uma relação entre festividades e luta. Sempre massivos, por vezes são realizados nas capitais dos estados ou nos municípios.

Os encontros estaduais de Sem Terrinha, até 1996, levavam o nome de Congresso Infanto-Juvenil, mas no primeiro Congresso Infantil Estadual de São Paulo, com o lema "Reforma Agrária uma luta de todos e dos Sem Terrinha também", e depois do "manifesto dos Sem Terrinha ao povo Brasileiro", as crianças passaram assumir o nome Sem Terrinha. A partir do ano de 1997, em todo Brasil, os encontros regionais e estaduais passaram se chamar Encontro e Jornada dos Sem Terrinha. (SILVA; FELIPE \& RAMOS, 2012, p. 420).

Os encontros se tornaram uma cultura do MST e todos os estados onde o MST está organizado realizam, em outubro, atividades que hoje fazem parte das suas jornadas de luta.

Os temas discutidos estão ligados ao processo conjuntural. Como exemplo, pode-se citar a primeira atividade estadual com crianças Sem Terra, que foi chamada de Congresso Infanto-Juvenil e foi realizada em 1994, no Rio Grande do Sul. No ano de 1996, no estado de São Paulo, o congresso teve como lema Reforma Agrária uma luta de todos e dos Sem Terrinha também.

Os outros temas tiveram uma relação com o concurso de redação e desenho que o MST promoveu para as escolas de acampamentos e assentamento. Entre outros: Desenhando o Brasil - $O$ Brasil que queremos (1999); Movimentos Sem Terra: por escola terra e Dignidade (1997); MST, quando anos você Tem? Terra e Vida (2003); As Sementes são Patrimônio da humanidade (2005); e mais recente um tema proporcionado pela campanha que o MST fez em 2011, Fechar Escola é Crime (2012).

Para acontecer os encontros, são realizadas preparações nos acampamentos e assentamentos no sentido de discutir com as crianças suas necessidades e de suas comunidades tendo como objetivo a elaboração de uma pauta coletiva de reivindicação estadual com as crianças.

A jornada é um lugar de encontro, de festa, de brincadeiras, de luta e negociação da pauta. Cada região organiza uma equipe de negociação das crianças para discutir com as prefeituras, secretarias municipais de educação e secretaria de estado da Educação. Nos últimos 4 anos, o MST tem mobilizado, em todo Brasil, em torno de 12 a 15 mil crianças nas jornadas. "Em 2010, podemos arriscar dizer que a Jornada Sem Terrinha foi uma das principais ações que o MST realizou em nível nacional. Foram 14 estados, com o número aproximado de 15 mil crianças mobilizadas em todo o Brasil" "." Pode-se frisar a importância da ação e, consequentemente, do lugar atribuído à criança, quando o documento afirma ter sido esta uma de suas principais ações, naquele ano. Cabe dizer que esse é reconhecido como um espaço de formação muito importante para as crianças e de aprendizado pelo conjunto do MST e sua significação no contexto da luta pela terra. 


\section{CIRANDA INFANTIL}

A Ciranda Infantil, nos diferentes documentos do MST, é afirmada como espaço/tempo necessário de acontecer nos acampamentos e assentamentos (com caráter permanente e com periodicidade) e em todos os momentos em que o Movimento realiza suas atividades, como: marchas, reuniões, congressos, assembléias etc. (nesses casos, ela é chamada de itinerante). Ciranda Infantil foi o nome dado ao espaço educativo das crianças Sem Terrinha e tem como base referencial e originária a participação das mulheres do MST.

No primeiro momento, a criança apareceu como um problema para as atividades no Movimento. A participação da mulher nos cursos, reuniões e outros espaços coletivos não tinha como ser ampliada sem a criação de espaços e atividades que pudessem levar em conta as crianças. Essa participação se dava no trabalho das cooperativas, no processo da luta empreendida pelo movimento, enfim, na ocupação das mulheres nos diferentes espaços organizativos do MST.

Em um segundo momento, a criança aparece como preocupação no sentido do cuidado e da atenção em ter um lugar para que ela pudesse ficar bem cuidada e que as mães não tivessem preocupações ao deixá-la naquele espaço.

Num terceiro momento, a criança aparece no movimento sendo pensada em ambiente de formação, de inserção e construtora da luta juntamente com a família. Esses três momentos ocorrem não de forma linear, mas no contexto da luta pela terra. E são permanentes, pois além do MST não estar isolado das discussões que permeiam em geral nossa sociedade, novas pessoas chegam aos acampamentos cotidianamente e o processo de formação é uma necessidade constante.

Segundo a pesquisa de Araújo (2009, p.87), "As Cirandas Infantis Permanentes surgem no Setor de Produção, Cooperação e Meio Ambiente. O Movimento começou a organizar as cooperativas de produção agrícola nos assentamentos entre os anos de 1989 a 1995" A necessidade das mulheres se inserirem no trabalho das cooperativas vai, portanto, proporcionar um debate sobre o lugar da criança nos assentamentos.

Nesta direção, o "estado do Ceará foi o pioneiro nessas experiências, impulsionando o coletivo nacional de educação vai discutir, em 1996, pela primeira vez a educação infantil" (MST - documento interno, 2006). Em 1995, essa experiência era denominada de Creche ${ }^{4}$. O debate surge pela necessidade das mulheres militantes do estado do Ceará, atuar no Movimento. Em sua maioria, por motivos de cuidar dos filhos, deixavam à militância. Desta forma, pensaram em uma alternativa para participação da mulher no MST, organizando um espaço para deixar as crianças enquanto trabalhavam. Reivindicaram da $\mathrm{UNICEF}^{5}$ de Fortaleza uma Creche Itinerante que, em homenagem a uma criança que faleceu no assentamento, passou a ser chamado de Paloma e, com o passar da história, de Ciranda Infantil Paloma.

Em 1996, na cidade de Santos, o setor de Educação Nacional realiza uma de suas reuniões e define o nome de Ciranda Infantil como espaço formador das crianças Sem Terra. E a partir dessa experiência, o MST, em nível nacional, através do setor de educação, realiza atividades com as crianças e organiza a primeira Ciranda Infantil nacional em 1997, no primeiro Encontro Nacional de Educadores da Reforma Agrária - ENERA, com 80 crianças.

O nome que foi sendo construído inicialmente nesse processo era o de círculos infantis baseado na experiência cubana. Mas, fomos construindo uma identidade própria, na qual se concretizou a Ciranda Infantil, nome que se refere à nossa cultura popular, às nossas danças, brincadeira, e à cooperação, à 
força simbólica do círculo, ao coletivo e ao ser criança. (documento interno, $\mathrm{p}$ $3)^{6}$

E a Ciranda vai tomando corpo e se torna um espaço de cultura no MST. A partir da Marcha de 2005 e das reflexões que foram realizadas, a Ciranda Infantil tornou-se uma tarefa assumida pelo conjunto do MST e tem o trabalho com a infância Sem Terra como o centro de seu interesse.

A Ciranda se constitui, portanto, como um território da infância no MST, um espaço que ela pode ocupar e criar suas referências. É a partir desse espaço coletivo que outras vertentes da vida da criança se interpenetram, juntando a experiência de participar da luta do Movimento, a relação com a escola, o cotidiano na família e o dia a dia que vive como acampada ou assentada. A participação das crianças e adolescentes nesse espaço ganha significação para os acampamentos e assentamentos, como também para as atividades gerais do MST.

\section{COMUNICAÇÃO E CULTURA}

Durante o processo histórico de constituição do Movimento e as suas reflexões sobre a criança, foram produzidos alguns materiais como Fita K7; CDs; livretos de cantigas infantis e literaturas. O que levou o MST a organizar essas produções foi à realidade vivida nos acampamentos e assentamentos e a necessidade de instrumentos de comunicação nesses e entre esses contextos. Além disso, a falta de acesso a materiais que dialogassem com o próprio Movimento fez com que ele, por meio do coletivo nacional de educação, experimentasse o exercício de produzir coletivamente literatura, canções infantis, reflexões sobre os processos educativos.

Inicialmente, a referência e inspiração para a produção dos materiais foram as experiências cubanas. Educadoras e educadores do MST vivenciaram um processo de intercâmbio e solidariedade internacionalista conhecendo as práticas de educação em Cuba. A socialização dessa experiência desencadeou ações concretas no conjunto da organização. Motivado pela experiência cubana, o setor de educação organizou um Curso Nacional de Pedagogia, realizado em Belo Horizonte, em 1994. Este curso contou com várias oficinas de produções de arte e literatura para as frentes de Educação de Jovens e Adultos - EJA, Educação infantil e Educação Fundamental. Essas oficinas tiveram o objetivo de fazer produções coletivas para as diferentes idades.

\section{A) AS CANÇÕES INFANTIS}

Dentre as diferentes possibilidades de linguagens no processo de comunicação, o MST tem a musicalização como uma prática privilegiada nas diferentes atividades além de inseri-la no desafio, para o seu conjunto, da produção e criação coletiva no campo da arte.

A primeira Fita K7, nomeada de "Plantando Cirandas", foi resultado de um trabalho coletivo realizado na oficina de educação para produções de músicas infantis e literaturas, que aconteceu em 1994. As canções vão trazer a força da luta, como afirma a letra da música Ocupação (1994, p.10 e $11)$,

pra entrar na ocupação, tem que ter união.

Oba! Agora já posso entrar.

Pra entrar na ocupação temos que resistir, que cooperar, que produzir, que repartir que educar. 
Outra versão desse processo de musicalização para as crianças foi a produção homônima, agora em formato CD, produzido em 1998, em um processo um pouco diferente do primeiro. Para a organização do $\mathrm{CD}$, as composições de caráter individual, contaram com a participação de artistas amigos do MST. As canções se apresentam em uma linguagem infantil e trazem os animais, a floresta, a terra, a brincadeira como elementos fundamentais. Na canção Roda Ciranda (1998, p.12),

Criança pra ser feliz, não pode fugir da moda

Tem que fazer ciranda, tem que brincar de roda

Pipoca, amendoim torrado

quero ver você nesse requebrado

\section{B) AS LITERATURAS INFANTIS}

Em relação à produção de literatura para a infância, as primeiras produções também datam de 1994 e têm como principal temática os conteúdos relativos à história do Brasil. Esse trabalho foi direcionado para as escolas por conta da realidade de escassez deste tipo de material e da necessidade dos Sem Terrinha terem acesso nos acampamentos e assentamentos, bem como para o trabalho pedagógico desenvolvidos com as crianças em seus diferentes espaços. O setor de Educação, para garantir a identidade das produções, organiza algumas coleções: Fazendo Escola; Fazendo História; Caderno de Educação; e Boletim de Educação. A coleção Fazendo História, por exemplo, é composta por 6 livros destinados às crianças dos acampamentos e assentamentos.

A partir do V Congresso (2007) e do $1^{\circ}$ Seminário Nacional sobre a Infância (2007), os setores de Cultura, Comunicação e Educação têm produzido, nos últimos 6 anos, um material específico para as crianças. O primeiro material de caráter coletivo foi o Jornal das Crianças Sem Terrinha. O primeiro jornal foi publicado, em outubro de 2007. No ano seguinte, as edições foram incorporadas como encarte ao Jornal Sem Terra, de periodicidade mensal, e passaram a contar com um planejamento temático com objetivos de ser não somente para, mas também das crianças. $\mathrm{O}$ Jornal, planejado anualmente, possui uma tiragem de 10 mil exemplares mensais e sua distribuição é realizada para todos os estados do Brasil.

No ano de 2013, o Jornal das Crianças Sem Terrinha completou 6 anos. É uma novidade em um movimento campesino ter encarado o desafio de escrever para crianças e adultos.

Outro material produzido pelo MST direcionado às crianças é a Revista Sem Terrinha. No ano de 2009 , foi publicada a $1^{\circ}$ edição, com o objetivo de ser uma produção voltada para as crianças, com uma periodicidade anual. Trata-se de uma produção que procura trazer a história contada de forma crítica, dos movimentos sociais e dos países, por meio da arte, das brincadeiras e de jogos, com a intenção de garantir que as escolas tenham acesso à Revista como também aos diferentes espaços educativos das crianças do MST.

Após realizada essa breve contextualização das ações do MST em relação à infância, que constituem o pano de fundo dos materiais e documentos produzidos pelo Movimento, apresentarei a análise dos documentos levantados na pesquisa. Esta análise obedece as três categorias citadas anteriormente na metodologia: produções sobre a infância; produções para as crianças; produções para e com as crianças.

\section{A PRODUÇÃO SOBRE A INFÂNCIA}

Do total levantado na pesquisa, 7 documentos referem-se à produção sobre a infância, e deste dois foram escolhidos para análise. Estes documentos são produções que trazem relatos de experiência 
da luta pela terra, da organização das jornadas de Sem Terrinha, de orientação para educadores no trabalho com a criança, orientação para o debate com a base Sem Terra sobre a infância.

Em relação aos dois documentos escolhidos para análise (Caderno de Educação n 12, 2004; Caderno da Infância $\left.{ }^{\circ} 1,2011\right)$, ambos trazem como reflexão a criança como sujeito, em formação na luta e a sua relação com a vida no acampamento ou assentamento.

O Caderno de Educação ${ }^{7} n^{\circ} 12$ Educação Infantil: movimento da vida, dança do aprender (2004), é uma produção composta por 58 páginas e destina-se tanto para pessoas do Movimento, em especial, do setor de educação e educadores das Cirandas Infantis, como para demais pessoas interessadas em conhecer a proposta de educação para a infância.

Segundo o MST (2004), o Caderno $n^{\circ} 12$ é fruto da sistematização das práticas realizadas nas Cirandas Infantis Itinerantes (marchas, reuniões, congressos, entre outras) e das Cirandas Infantis permanentes nos acampamentos e assentamentos da Reforma Agrária.

O documento recupera a história da Educação Infantil, trazendo uma contextualização desse processo nas lutas das mulheres no mundo do trabalho. Informa também, que os primeiros atendimentos à criança, no Brasil, foram feitos por mulheres, assim como os movimentos de reivindicação de ampliação de vagas por creches. Também nele aparecem algumas perguntas que o MST se faz no sentido de colocar em pauta a necessidade da Educação Infantil: "porque tantos nomes para denominar esse atendimento - creche, maternal, jardim de infância, pré-escola, etc; como também das pessoas que nele atuam - atendente, pajem, babá, recreadora, monitora, educadora, professora? Porque que todas que aí trabalham são mulheres?” (MST, 2004, p.13). Esse talvez seja o ponto fundamental para o aprofundamento no contexto histórico dos cuidados e educação da criança na sociedade e no próprio Movimento, que reserva à mulher o papel de principal responsável.

A significação da criança expressa no documento é de uma criança que não está separada do conjunto dos demais segmentos etários que compõem o Movimento. Ela faz parte da luta pela reforma agrária e pela transformação social desde sua origem, vinculada principalmente às mulheres. A Ciranda, umas das atividades que foi sendo forjada a partir da necessidade das mulheres, tornou-se com o tempo um referencial para a criança Sem Terra no MST. Sua significação, aos poucos, transita e inclui a criança para além da necessidade da mãe, o que estava bastante presente na sua proposta inicial.

Às duas necessidades originárias que motivaram a criação da Ciranda Infantil, (participação da mulher no trabalho e na militância), foi somada uma terceira: a organização de um espaço específico para as crianças.

A concepção de infância do MST, na década de 90, está centrada no movimento pedagógico realizado pelo MST a partir da necessidade das famílias e, principalmente, da realidade das mulheres e das relações de gênero vividas no Movimento.

Em alguns trechos, é possível verificar que o setor de educação, autor do documento, coloca como desafios a necessidade de pautar a criança como construtora do Movimento. Aponta assim a necessidade de uma reflexão conjunta sobre as relações sociais que se estabelece para e com a criança. Ou seja, o setor de educação cria uma tensão para o conjunto no sentido de pautar a reflexão sobre a criança e seu lugar no Movimento, inclusive concebida como a continuidade do MST. Para isso, indica que sua formação é determinante para a construção da identidade Sem Terra, desde a infância. Para o setor de educação o espaço infantil, "a ciranda não pode ser vista apenas como um direito dos pais e das mães que participam do MST, mas principalmente como um direito das crianças que também são sujeitos construtores do movimento". (MST, 2004, p.37 grifos nossos). Nesse sentido, a criança deve estar na organização, dentro de um planejamento das atividades, não por questão de logística organizativa dos espaços, mas por uma concepção político-pedagógica da infância no Movimento. 
O documento de 2011, Caderno de Educação da Infância Sem Terra: orientações para o trabalho de base (2011) é composto por 72 páginas. É de acesso interno do MST e tem como objetivo "iniciar o debate e a reflexão coletiva sobre este tempo de vida que é a infância" (MST, 2011, p.7). Este caderno sobre a infância é reconhecido como um material orientador para o debate coletivo, ou seja, foi construído na perspectiva de dialogar com as famílias e o conjunto do Movimento sobre a infância. Qual significado desse caderno para o trabalho com a base? E qual o sentido da abertura de uma nova coleção para infância no MST? Essas questões emergem nesse trabalho, porém precisam de novas pesquisas para ajudar a respondê-las.

Na elaboração do caderno, refletiu-se sobre a ausência de documentos para o debate com a base, motivo pelo qual ele é escrito com uma linguagem popular, didática e organizativa. Em sua elaboração, foi proposta uma metodologia que dialogasse com a base através de encontros, retomando o método de trabalho de educação popular através do debate sobre a infância.

A metodologia proposta por esse material de trabalho com a base prevê 5 encontros: $1^{\circ}$ ) A infância: que tempo de vida é este?; $2^{\circ}$ ) A Família; $3^{\circ}$ ) A criança e a coletividade; $4^{\circ}$ ) $\mathrm{O}$ cuidar e educar; $5^{\circ}$ ) O Trabalho. Estes temas já indicam intencionalidades e campos de significações sobre a infância, quer seja, o desejo de problematizar e discutir a infância, considerando a criança permeada por relações, pela sua vinculação com a família, a coletividade e o trabalho.

Cada encontro é constituído com os seguintes elementos: mística, imagens, poesias, reflexões, contextualização da história da infância na sociedade e uma atividade prática na comunidade, como exemplo, a construção de um parque infantil. Esta proposta incita a comunidade a reconhecer que os espaços dos acampamentos e assentamentos precisam contemplar ambientes e equipamentos para as crianças e para o exercício de sua ludicidade, num processo de criação que medeia à apropriação do acampamento/assentamento pela criança.

Nos objetivos do caderno, é provocado o debate da relação infância e seus modos de vida com a família e com a coletividade. Um dos objetivos reafirma a importância de "Entender como a criança dos acampamentos/assentamentos vivem sua infância" (2011, p.7). As reflexões estão no sentido de resgatar o processo da história da infância, tendo como referencial a atualidade, expressão das relações sociais capitalistas, bem como a preocupação que o MST apresenta em relação à influência destas relações na vida das famílias e, em especial, das crianças. Estas reflexões revelam um pensamento contextual e histórico que configura-se para além de uma preocupação pedagógica com a criança.

A partir do séc. XVIII, as transformações provocadas pelo avanço do capitalismo - a solidificação da sociedade de classes, o avanço da ciência e da luta dos trabalhadores - é que vão atribuindo à criança um lugar social diferente dos adultos e vai dando outro sentido à infância. A criança não mais vista como o adulto que será, e a infância passa a ser compreendida como um tempo próprio de vida, com suas características e necessidades, um tempo a ser vivido por todo o ser humano.

No capitalismo, o período da infância se torna importante também para preparar o novo consumidor, o trabalhador obediente e disciplinado, que não reage, não se organiza e aceita a realidade como está. Muitos fatores têm contribuído para que nossas crianças não viva sua infância.

[...] O MST entende que o ser humano se faz em toda sua existência, sendo que nos primeiros anos de vida é que se constroem as bases dos valores e princípios da vida em sociedade. (IDEM, 2011, p. 12 -14 grifos nossos). 
A perspectiva de análise proposta pelo MST, ao considerar a perspectiva da história da infância, e da infância como um tempo fundamental para formação do sujeito, coloca em questão como as relações hegemônicas formam a criança enquanto consumidora, passiva e como futura trabalhadora. A pergunta que o MST faz para a base sobre esta questão é posta da seguinte forma: "A destruição promovida pelo capitalismo e que provoca na humanidade uma crise de valores e princípios, será que isso atinge as nossas crianças? Nós já perguntamos como ela enxerga e constrói o mundo a sua volta?" (2011, p. 25). Desta forma, situa a reflexão dos membros do Movimento para a problematização da criança na sociedade capitalista e nos valores inerentes a ela. Também indaga sobre as possibilidades de ações contra a hegemonia presente na formação das crianças no MST.

O MST provoca os Sem Terra a pensarem como está a organização das famílias em suas comunidades e, também, sua composição nos dias de hoje. Faz uma retomada histórica das diferentes formas da instituição familiar na sociedade e como se configura hoje a família camponesa, que passou por várias transformações ao longo da história.

O documento admite assim a existência de dinâmicas familiares múltiplas, diferentemente do modelo de família nuclear burguesa. Com isto, provoca reflexões na base, desconstruindo concepções naturalizadas e idealizadas de famílias. Ao mesmo tempo, reconhece que, em sua maioria, são as mulheres as responsáveis pela educação e cuidado dos filhos. As relações sociais existentes tanto na cidade quanto no campo são a materialidade em que se assenta a preocupação do MST, colocando como responsabilidade da família Sem Terra (nessa nova configuração) a organização da vida coletiva. A centralidade está na família que promove a coletividade. Ou seja, a coletividade possibilitaria à criança um lugar que apresente valores que se contrapõem aos valores capitalistas. A importância da coletividade na formação da criança e a referência de que a criança se educa nas relações que estabelece, desde o local onde ela vive, são determinantes para a formação desta criança. Afirma o MST que

Precisamos entender que as crianças têm iniciativas, têm opiniões, e que, muitas vezes, ao questionarem os adultos em suas atitudes, impulsionam mudanças. Se observarmos atentamente e dermos espaço é possível vermos na auto-organização das crianças em suas atividades e na relação com os adultos a criação de coisas novas e autênticas. (2011, p. 25 - 26 grifos nossos).

Destaque pode ser dado para o reconhecimento da criança como sujeito que muda o grupo, cria coisas novas e que, com iniciativa, evidencia ainda uma capacidade de auto-organização.

No reconhecimento da inserção da criança no mundo e da mediação exercida sobre os meios de comunicação na construção cultural da criança, o documento expressa um conjunto de preocupações direcionadas em refletir sobre o cuidar e o educar, fortalecendo esse espaço da criança e, especificamente, o instrumento de comunicação dos adultos e das crianças como uma das ferramentas contra hegemônicas, no processo formativo da criança, imersa nas contradições da realidade que vive infância.

Em síntese, constatamos que os dois documentos analisados trazem apontamentos para reflexões dos adultos sobre a criança e a infância, desde o pensar as atividades, ações e o cuidar, relativos ao papel desempenhado por educadores, como a revisão e problematização de práticas educativas, circunscritas à responsabilidade familiar. Se o primeiro documento analisado procura 
trabalhar uma concepção e uma orientação para os educadores/as do MST, responsáveis por organizar o trabalho com a infância nos estados, o segundo expande os adultos destinatários do documento.

Os documentos trazem a preocupação que o MST tem com a infância, a ampliação da reflexão na relação geracional e a preocupação com a continuidade do próprio Movimento na história.

Cabe dizer ainda que, diante das várias questões sobre a infância que aparecem nas duas produções, em particular no Caderno de 2011, nenhuma delas indica perguntas que poderiam ser feitas para a escuta das crianças, sobre, por exemplo: os que elas pensam de sua participação? E sobre seus direitos? Como elas veem o assentamento? Ou como gostariam que fosse?

\section{A PRODUÇÃO PARA AS CRIANÇAS}

Do total de materiais levantados, 14 referem-se às produções para as crianças.

As produções Para as crianças estão voltadas para o campo da literatura, com histórias da realidade da luta pela terra, da poesia, da música e da comunicação infantil. As publicações mais recentes são as cinco Revistas das Crianças Sem Terrinha. Dentre as produções de coleções, a última foi produzida em 2001. Em 2009, inicia-se a produção da Revista, que marca praticamente oito anos sem produção literária sistemática do MST para suas crianças.

Em relação aos textos escolhidos para análise com maior profundidade: A comunidade dos

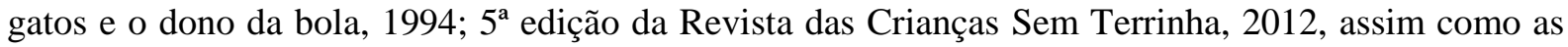
demais produções, caracterizam-se por uma preocupação em também mediar à relação com a criança por meio da linguagem escrita.

O livro intitulado "A comunidade dos gatos e o dono da bola" (Coleção Fazendo Escola, $\mathbf{n}^{\circ} \mathbf{1}$, 1994) contém duas estórias e é composto por 29 páginas. É uma produção escrita que articula a literatura e o desenho. Sua autoria é de educadores do Setor de Educação do MST do curso nacional de Pedagogia em Belo Horizonte, 1994, e é uma primeira produção coletiva voltada para as crianças. Ela é indicada na sua apresentação para o público infantil e infanto-juvenil. Seu conteúdo permite um debate com as crianças sobre a importância da organização coletiva, da solidariedade e do respeito ao processo da organização da comunidade. O MST afirma que esse documento,

(...) surge para atender mais especialmente essa grande gente miúda, que são as crianças e jovens assentadas ou ainda acampadas de todo Brasil. Crianças e jovens que sonham que cantam e encantam. Que alimentam esperanças, que dão coragem, que são perseverantes. Que expressam ternura, carinho, medo, paixão, e que também sabem da importância de estudar bastante para ajudar o MST a crescer. (MST, 1994, p. 3 grifos nossos).

A criança aparece na apresentação do documento no seu aspecto expressivo, mas também como expectativa de continuidade do Movimento, ou seja, numa perspectiva instrumental para o crescimento do Movimento.

A Comunidade dos Gatos apresenta uma metodologia dialógica com a criança fazendo diferentes perguntas no início da história "Você já ouviu falar que gato vira tigre?", dentre outras estimulando a curiosidade da criança.

O livro infantil traz a ideia de comunidade e coletividade, um lugar onde as famílias vivem juntas. No período da produção do livro, a palavra de ordem que marca as produções do MST era "Ocupar, Resistir e Produzir", momento de fortalecimento da organização da produção e do assentamento. A literatura infantil vai afirmar que 
em uma comunidade, não muito longe daqui, vivia uma colônia de gatos e era muito bonita. Havia casas para todos, havia comida e eles eram muito alegres. Faziam festas em dias importantes para eles, cantavam e dançavam. Os grandes e pequenos viviam juntos trabalhando, se alimentando e crescendo junto. (IDEM, 1994, p. 7)

A idéia de lugar ideal, sem problemas e de um coletivo com unidade, e também do trabalho coletivo, são questões presentes no texto inicial da história. Mas a comunidade de gatos, registrada nesta literatura, assim como toda a sociedade, não está isolada das influências sociais capitalistas. Um grupo ao buscar comida na mata, acaba se perdendo, ficando muitos dias longe da comunidade. E um dos gatos, pela fome que sentia e pela falta de uma consciência coletiva, começou a pensar que "se eu comesse aquele bichano, poderia ficar forte e então não comeria mais mato" (1994, p.11). Neste sentido a reflexão presente nesta história, afirma a limitação das atitudes individualistas, combatidas pelo MST, em contraponto trazendo a preocupação da comunidade em se organizar coletivamente para não permitir que mais gatos se percam no individualismo. Desta forma, busca-se reafirmar o valor de que a unidade é o caminho para a organização.

Na segunda história presente nesse material, intitulado: $O$ dono da bola há a estória de um menino que tinha tudo, inclusive uma bola, porém brincava a maioria das vezes, sozinho. A sua relação com outras crianças, era de individualismo. Demonstrava ter dificuldades em se relacionar porque sempre queria que as suas regras predominassem. "Daniel não concordava com as regras; a todo momento ele queria ser o primeiro em tudo: não queria perder o poder da bola, fez pose com ela o tempo inteiro e brincava sozinho. Não havendo acordos, o jogo não aconteceu". (IDEM, 1994, p.26). E foi num assentamento, em que Daniel aprendeu a se relacionar de forma mais afetiva e humana com os meninos, pois ele observou que "todos jogavam com garra, alegria e sem brigas" (IDEM, p.28), a convivência no assentamento permitiu que se deparasse com uma nova forma de organização e sentido pra vida, em particular numa nova forma de brincar, que até então ele pouco exercitava.

O valor do coletivo é, portanto, o mote do livro, ao colocar o assentamento como lugar de felicidade. Fica evidente o uso da literatura como instrumento de transmissão de uma moral e de um sentimento de pertencimento, uma oferta de identidade, mais do que uma linguagem que deve ser trabalhada em si mesma pelas potencialidades e fantasias que ela permite.

No entanto, ficam algumas perguntas: Que relação o MST estabelece com crianças e jovens quando produz um material específico para eles com essas perspectivas?

O documento também reforça a participação masculina nas estórias, tanto a Comunidade dos Gatos que só tem referências aos gatos que não tem nomes. E $O$ Dono da bola que é um menino e sua relação com o futebol e um grupo de meninos. Será que nas comunidades as meninas não jogam futebol com os meninos? Qual a intencionalidade da literatura na relação de gênero? Desta forma, esteve ausente uma reflexão nessa direção.

A $5^{\circ}$ e última edição da Revista das Crianças Sem Terrinha, de 2012, tem duas temáticas centrais. A discussão sobre o VI Congresso do MST, realizada por meio de uma reunião das crianças e a história de Layla e Samir: o sonho de duas crianças Palestina.

Cabe lembrar que A Revista das Crianças Sem Terrinha, instrumento de comunicação das crianças, foi lançada em $1^{a}$ edição especial no ano de 2009, no encontro nacional dos 25 anos do MST, no Rio Grande do Sul. No período de sua última edição estava atrelado a realização do VI Congresso ${ }^{8}$.

A $5^{\circ}$ revista é composta por 28 páginas e organizada por meio do estabelecimento de um diálogo de crianças, realizado pela editorial da revista, com as crianças do Brasil. Ela é apresentada de 
forma animadora e com certa euforia com a produção do material. No índice, por meio do uso de várias cores, constam as temáticas trabalhadas na revista. São desenvolvidas duas histórias, brincadeiras, receita de purê colorido, o significado da bandeira do MST, música, fotografias de diferentes lugares, crianças e muitos desenhos.

O primeiro diálogo com as crianças busca estimulá-las a entrarem na história mais ampla de seu grupo, na intenção destas se sentirem-se envolvidas nesse processo de da organização e preparação para o VI Congresso. A história trabalha com 4 personagens infantis (meninos e meninas), 1 personagem idoso e 4 personagens adultos. Abaixo um trecho do diálogo:

Sara: Eu tenho uma ideia! Que tal a gente construir um grupo para irmos para ao Congresso do MST em Brasília?

Antonio: Mas isso o assentamento já esta discutindo! Estão estudando e fazendo um monte de reunião para organizar tudo.

João: Mas as criançadas não estão participando... Taí, gostei da ideia! A gente poderia fazer as nossas reuniões, como se a gente fosse a coordenação, entende? Mas ninguém precisa saber! (IDEM, 2012, p.2).

O que aparece é a preocupação do MST em relação à participação das crianças no VI Congresso e por meio do diálogo imaginário entre elas, procura estimular a organização das crianças, tencionando com o espaço adulto por meio da reivindicação da participação de forma organizada. $\mathrm{Ou}$ seja, se os adultos estão estudando e fazendo reuniões, por que as crianças não estão participando. A estória estimula a conspiração infantil, desde a organização do espaço da reunião infantil, que se dá no parque infantil do assentamento, à pesquisa que farão buscando informações sobre o congresso. Esta conspiração afirma-se pela manutenção do segredo da investigação que estão realizando e as descobertas que vão tendo sobre o próprio Movimento.

Entendi que o Congresso é como se fosse a assembléia de nosso assentamento, onde tomamos as decisões discutidas pelos núcleos de base, assim o Congresso é um grande encontro com representações de todos os estados em que o movimento está organizado e lá tomamos decisões que já foram discutidas por todos. (IDEM, 2012, p. 6)

A Revista das Crianças Sem Terrinha, $\mathrm{n}^{\circ} 5$, mostra o esforço que o MST vem fazendo para que sua concepção de mundo, ou seja, de movimento político e popular com suas formas organizativas cheguem até as crianças. O MST, de forma simbólica, reflete sobre a organização do assentamento, bem como da inserção política ser realizada desde infância.

Na história de Layla e Samir: Os sonhos de duas crianças na Palestina é abordado o tema do internacionalismo e da campanha de solidariedade às crianças palestinas que o MST tem organizado.

A realidade da Palestina foi contada em forma de história para as crianças Sem Terrinha, por meio de uma representação de crianças deste país trazendo a sua luta, a sua vida cotidiana e seus sonhos. A infância Palestina é caracterizada por meio de sua vivência na escola, pela caminhada toda sexta-feira para plantar oliveiras, pela presença na manutenção da resistência em seu país junto com os adultos. A vivência da infância aparece associada aos soldados israelenses, com a presença de bombas e com prisões. Um muro que separa as infâncias palestinas e israelenses é apresentado como aquele que, embora existente, não tira o sonho de liberdade e resistência. 
Um dia Layla contou na escola: Foi um dia muito triste. Quando as primeiras árvores foram derrubadas, e tiveram suas raízes arrancadas com toda força e violência, caíram lágrimas do rosto do meu avô, que falou que tinha plantado com as próprias mãos aquela belas árvores no ano de 1948, ano que foi criado o estado de Israel. Layla disse que o avô plantou aquelas árvores dizendo que nunca iria deixar aquelas terras, e que sempre iria cuidar das oliveiras. O avô de Layla, seu Mohammad, tinha dez anos quando plantou sua primeira oliveira na vila. (IDEM, 2012, p.22)

A relação das gerações para o MST é muito forte e na história palestina se reafirma essa relação com o tempo histórico, provocando efeito de continuidade na formação das crianças. A solidariedade internacionalista entre os povos apresenta-se como um dos valores que o MST, nos 29 anos de existência, tem reafirmado através dos documentos e práticas de vivência com outros povos, nos diferentes continentes. Em relação à Palestina, inclusive nas colheitas de oliveiras, uma brigada de militantes tem participado dessa experiência de resistência. Ao contar essa experiência, afirma que

hoje em dia, existem cinco mil pessoas nas cadeias de Israel. São homens e mulheres palestinas que lutam por justiça, igualdade, democracia e liberdade nacional. Desses presos, 192 são crianças de até 16 anos de idade. Alguns presos palestinos estão na cadeia há 27 anos (2012, p. 27).

Essas são algumas informações que as crianças Sem Terrinha tiveram acesso por meio da Revista, que provoca uma partilha de experiência para além dos limites do assentamento, do Movimento e do país. A relação de identificação se dá por meio da exploração dos aspectos da luta e da vida difícil das crianças. O objetivo em trazer essa temática para as crianças explicita também um desejo em estimular as crianças desde pequenas a serem solidárias com outros povos.

Em síntese, as duas produções trazem uma criança que está sendo pensada e projetada por adultos. O diferencial da Coleção Fazendo História n ${ }^{\circ} 1$ e da Revista das Crianças Sem Terrinha n 5 , é que entre uma e a outra são 19 anos de distância no tempo da produção. Portanto, possuem diferenças seja na perspectiva de linguagem (dos desenhos, do colorido, do desenho gráfico, das imagens) seja no acúmulo ocorrido por meio de outras produções e debate que foram intermediários no processo para se chegar à Revista.

Sendo a Comunidade dos Gatos e $O$ Dono da Bola uma primeira literatura, apresentam mais marcas da linguagem do adulto, como também há uma certa idealização da criança, como do próprio Movimento, ao desconsiderar as contradições existentes nestes. A Revista $\mathrm{n}^{\circ} 5$ fortalece a imagem e as significações do MST, mas a linguagem tem uma relação de maior cuidado com as palavras, tem um diálogo mais próximo das crianças, procurando também, ampliar o horizonte da criança para outros lugares, a exemplo da Palestina. O que resta saber é se as histórias do Congresso de fato têm permitido à criança participar das discussões em preparação ao VI Congresso. 


\section{PRODUÇÃO PARA E COM A INFÂNCIA}

Do total de títulos, 5 foram classificados nessa categoria.

Para chegar a essa categorização, foi escolhido documentos que de alguma forma sistematiza a participação da criança e, entre essa participação, estão depoimentos sobre o processo da luta pela terra, poesias, brincadeiras, desenhos, participação nas músicas e falas no documentário. Destaca-se ainda que essa produção circunscreve-se ao âmbito da educação e da comunicação.

Como pudemos verificar, os anos de 2007 e 2009 foram aqueles em que o MST mais investiu nas produções de comunicação para a infância. Além da criação da revista, discutida no item anterior, também foram produzidos um jornal e um documentário. Trata-se de uma produção coletiva dos setores de Cultura, Comunicação e Educação e, juntamente com as escolas, as atividades das Cirandas Infantis e as Jornadas dos Sem Terrinha têm produzido documentos importantes para esse instrumento de comunicação.

O Jornal das Crianças Sem Terrinha (2007) e o Documentário Sem Terrinha em Movimento (2009) foram escolhidos para análise em virtude da maior evidência de participação da criança.

O Jornal das Crianças Sem Terra, na edição ${ }^{\circ}$ 1, (2007), foi realizado no ano das discussões e no calor do V Congresso. Ele nasce como encarte do Jornal Sem Terra, que é distribuído aos 24 Estados onde o MST está organizado e é um instrumento de comunicação das Crianças Sem Terrinha.

No jornal $\mathrm{n}^{\circ} 1$, existe um editorial, histórias e cantinho da diversão. $\mathrm{O}$ editorial anuncia que dois personagens do livro "História de Rosa" - Rosa e Natalino irão apresentar o jornal. O jornal n ${ }^{\circ}$, como todo processo de criação dos materiais analisados, tem a presença mais forte da linguagem adulta na produção. O jornal é uma sistematização da experiência do V Congresso e traz como título na capa "Por escola, terra e dignidade". O editorial carrega com as palavras no sentido de valorizar a conquista no MST de ter um jornal para as crianças,

Com grande alegria e honra que inauguramos nesta edição do Jornal Sem Terra, o Jornal das Crianças Sem Terrinha. Com certeza é mais uma conquista de nós Sem Terrinha, das famílias Sem Terra, de todo o nosso MST e de todas as crianças da classe trabalhadora. (2007, p. 2).

Essa primeira experiência foi uma conquista das crianças no próprio Movimento e o jornal relata a riqueza que foi a Escola e Ciranda Itinerante Paulo Freire, realizada no V Congresso, em 2007. A participação das crianças nos diferentes espaços, nas produções de poesias, visitando a feira da reforma agrária do Congresso, na audiência com o então Ministro da Educação, Fernando Haddad, na Rádio Brasil em Movimento, realizando um programa todos os dias. Também, por ser o mês de outubro, apresenta às crianças Che Guevara, contando sua história e a sua solidariedade internacionalista no mês de aniversário de sua morte. Mas, a forma da escrita, da linguagem utilizada, reflete o adulto falando para as crianças como criança e que afirma a importância desse instrumento como uma conquista para além do MST.

$\mathrm{Na}$ escola e na Ciranda realizada com as crianças, elas foram estimuladas a criam a partir do seu olhar em relação ao espaço a elas destinado no V Congresso. No Jornal, uma poesia produzida por Pedro, do acampamento Irmão Neves, de Minas Gerais, foi publicada. 


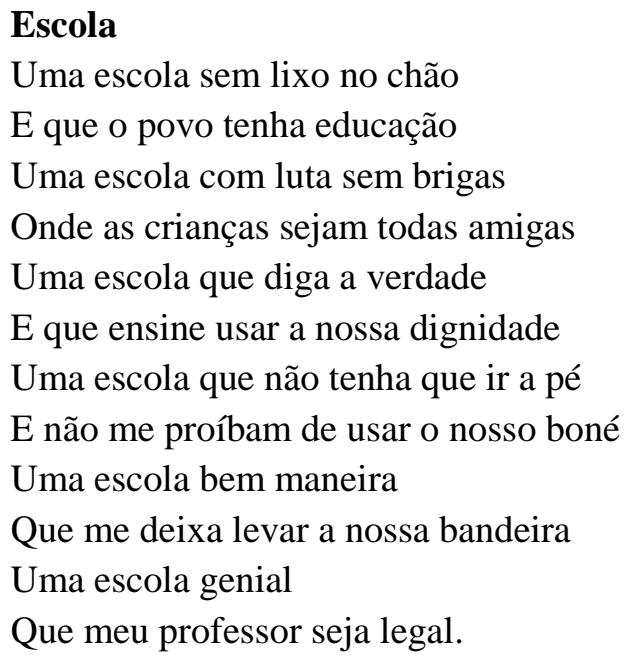

Consideramos que o Jornal das Crianças Sem Terrinha é instrumento de comunicação que tem proporcionado expressividade e a participação das crianças através das cartas, poesias e desenhos. A exemplo da poesia de Pedro, que participou de um processo em que, através do seu pensamento, pôde expressar em poesia o que ele espera de uma escola, tantas outras crianças nos acampamento e assentamentos podem tornar esse instrumento de comunicação uma ponte de articulação entre as crianças.

A comunicação é vista como ferramenta importante e, no caso do Jornal das Crianças, ele que já está no seu $6^{\circ}$ ano e na $41^{\circ}$ edição. No entanto, a partir desta análise surgem novas inquietações: Que reflexões o MST tem feito sobre essa importante ferramenta? A criança está participando da produção do jornal e tendo acesso ao jornal? Estas questões, longe de serem respondidas nesta pesquisa, apontam desdobramentos para novas pesquisas sobre as significações e as práticas do MST em relação à infância.

O Documentário Sem Terrinha em Movimento9 (2009), organizado pelos setores de Cultura, Comunicação e Educação, tem uma duração de 17 minutos. Essa produção teve a participação das crianças do início ao final do documentário. A partir das falas das crianças, nas diferentes atividades realizadas em nível nacional, o documentário é elaborado com a intenção de trazer para o conjunto do MST o protagonismo das crianças Sem Terra, por meio das atividades que são desenvolvidas nos Estados e pela contextualização da realidade da infância no Brasil.

A concepção de infância, em especial, ao retratar da infância brasileira destacada pelo MST, no documentário evidencia imagens das crianças trabalhadoras nos grandes centros, exploradas e que, nos seus depoimentos, apresentam dificuldade em explicitar e realizar os seus sonhos. E o documentário afirma que "ser criança, nem sempre é brincadeira", considerando o contexto social atual e as relações que o capitalismo estabelece para a vida humana. A partir dessa reflexão, traz as crianças na luta pela terra, nas ocupações, no enfrentamento com policiais na desocupação da terra, na vida sofrida das famílias e em especial das crianças nos acampamentos e assentamentos de reforma agrária. Reafirma o assentamento como o lugar da produção e reprodução da existência. Através dos desenhos animados realizados pelas próprias crianças, atualiza a afirmação de que a "criança, desde o surgimento do MST, está na luta".

O documentário, além dos depoimentos das crianças nos encontros dos Sem Terrinha e as palavras de ordem, evidencia a força da palavra da criança: “eu não quero sair do assentamento para 
morar na cidade. Eu gosto de lá. E ser Sem Terrinha é correr atrás do seu sonho”. Esta fala demarca a participação da criança Sem Terra e suas opiniões.

Os depoimentos de crianças nos assentamentos dão visibilidade ao pensamento e ao sentimento da criança acerca da vivência numa terra conquistada; "Eu gosto de morar aqui porque a gente vai pra represa todos os sábados e domingos, a gente planta o nosso alimento, a gente brinca com os vizinhos é muito legal aqui. Eu sou feliz. Já faz um tempo que estou aqui, eu gosto de viver aqui". "é uma luta muito boa dos Sem Terra e dos Sem Terrinha. Sem Terrinha somos nós, pequenos que vivemos na luta com nossos pais, nossas irmãs. Nós temos muitos amigos aqui".

Assim, o documentário Sem Terrinha em Movimento é uma produção que tem uma expressão forte da criança Sem Terra e foi um exercício do próprio Movimento em trabalhar com uma linguagem que atendesse ao público infantil e adulto. $\mathrm{O}$ desenho animado presente no documentário resultado de produção das próprias crianças no concurso de redação ${ }^{10}$ e desenho e está no livro Desenhando o Brasil (1998), assim como nos jornais e nas revistas das Crianças Sem Terrinha (2008 e 2009).

Esses dois documentos refletem o que tem de mais significativo do ponto de vista da participação da criança nas produções do Movimento. Eles revelam o quanto a criança conhece sobre sua realidade e ainda a capacidade que possui em produzir, refletir e propor um espaço para a sua autoorganização. O desafio que a análise dos documentos classificados nessa categoria aponta é o MST se colocar mais no sentido da realização de ações, com a infância e trazer mais as suas produções para a memória histórica em um Movimento camponês que luta pela terra e almeja a participação da criança na luta.

\section{CONSIDERAÇÕES FINAIS}

Os documentos do MST, desde as primeiras elaborações, descrevem a presença da criança e da infância no seu interior, em ações que vão desde o momento da ocupação pelas famílias as atividades e espaços pensados exclusivamente para as crianças. É visível que o grande intelectual da Infância é o Setor de Educação, que proporciona e provoca com intencionalidade o debate da infância para o conjunto do MST. Neste processo, ele busca trazer a sistematização das experiências com as crianças ao longo da história do Movimento. Considerando a forma organizativa do referido setor, por meio das frentes de trabalho, a Educação Infantil foi ganhando uma força maior com o envolvimento de outros setores (Gênero, Saúde, Produção, Comunicação e Cultura) tanto nos debates quanto nas ações promovidas para e com a infância.

As significações de Infância que se depreende nos documentos são: de uma criança pensada pelos adultos, que está na luta com a família; uma criança presente com a responsabilidade de continuidade da história do MST; uma criança que amplia o seu olhar na relação geracional que estabelece no Movimento; uma criança que provoca ampliação da reflexão do adulto sobre seus direitos, e sobre as formas como vive sua infância; uma criança por vezes que sofre violações estruturais da sociedade capitalista e também violações de direitos relativas a algumas práticas educativas.

Se a produção no geral é volumosa, quando consideramos a produção com a participação das crianças, ela é ainda muito tímida diante das demais produções, por exemplo, sobre a Infância. Entendo ser um desafio para o MST, cujo enfrentamento daria um grande salto no trabalho com a infância por meio da ampliação de produções com a participação efetiva da infância Sem Terra no processo de produção dos materiais. 
Os documentos, no geral, remetem-nos repetidamente aos três instrumentos que dão maior visibilidade à criança no MST: Jornada dos Sem Terrinha, Ciranda Infantil e o Veículos de comunicação da infância. Os documentos revelam uma forte idealização da criança no MST, como se ela estivesse protegida das relações de consumo e da cultura de massas, da violência, da mídia etc. A criança do assentamento e do acampamento sofre forte influências dos meios de comunicação, da escola, das relações capitalista estabelecidas. O que as diferencia é o movimento da luta que proporciona questionar essas relações, organizando ações concretas contra hegemônicas dando, assim, intencionalidade na formação da criança Sem Terra.

É notável a força de mobilização criada em torno da Jornada dos Sem Terrinha. Que envolve em nível nacional mais de 15 mil crianças no mês de outubro. Entretanto, além dessa dimensão, esta prática diferencia-se das práticas hegemônicas em relação às crianças no país, as quais, menos do que serem estimuladas a serem sujeitos, são objetos de intervenções e programas pensados, elaborados, efetivados e avaliados por adultos, bem como, por valores da sociedade capitalista (individualismo, consumismo, etc.). Trata-se assim de uma atividade que, no mínimo, necessita de ser investigada como forma contra-hegemônica de propiciar a participação política da criança na sociedade atual.

Nesta mesma linha, a Ciranda Infantil, no processo histórico do MST, caracteriza-se como fundamental para o fortalecimento da participação da mulher e da criança nas diferentes atividades. Por este motivo, como um espaço que proporciona a participação da criança no MST e é reivindicado pelas próprias crianças, também a Ciranda virou cultura no MST e o MST tornou a Ciranda uma referência nacional e internacional para as organizações campesinas. Na Via Campesina ${ }^{11}$ Nacional e Internacional, os Movimentos como $\mathrm{MAB}^{12}, \mathrm{MPA}^{13}$, no Brasil $\mathrm{MNCI}^{14}$ - Argentina, UNAC ${ }^{15}-$ Moçambique organizam hoje em suas atividades espaços para as crianças campesinas.

Por sua vez, os veículos de comunicação da Infância Sem Terra, em particular o Jornal das Crianças Sem Terrinha e a Revista Sem Terrinha constituem-se em veículos importantes assumidos nos últimos 6 anos pelo conjunto do MST e não somente de um setor. Também esses instrumentos, que ocupam espaço como uma ferramenta de comunicação do MST como o Jornal das Crianças Sem Terrinha, ganham significação não só pra as crianças, mas para o conjunto do MST. A Revista das Crianças Sem Terrinha que contém um conteúdo histórico que amplia ainda a dimensão da solidariedade entre as crianças dos diferentes povos estimula a conspiração coletiva para ter acesso à informação e à garantia da própria participação da criança no Movimento. É um veículo de comunicação infantil muito importante e que pode garantir a organização das crianças nos estados e a participação efetiva dela no processo da produção com a infância.

A criança Sem Terra tem ocupado um território neste tempo onde ela aparece como sujeito social e histórico, com a sua identidade e singularidade, a partir de reflexões e ações que permitem o exercício difícil de ser ela mesma. A singularidade da criança e das crianças Sem Terra está justamente na luta, são crianças que vivem nos acampamentos e assentamentos, que se relacionam com uma realidade de dureza e de conquistas e que as diferencia de outras infâncias.

O levantamento dos documentos e análise de parte de seus conteúdos sobre a infância tornaram assim evidente que, apesar de temas tão urgentes para um Movimento como o MST, no contexto da luta pela terra e pela reforma agrária, pensar e pautar a infância não é preocupação menor.

A forte vinculação da criança com sua família e a comunidade pode nos permitir dizer que a criança Sem Terra está também produzindo a história da classe trabalhadora, numa perspectiva de luta e de ocupação do seu espaço.

A pesquisa documental foi importante para trazer as produções que tratam da infância e os relatos sobre as práticas do Movimento que circunscrevem possibilidades de como os Sem Terrinha 
podem se constituir como sujeito coletivo. Mas para a continuidade da pesquisa e do aprofundamento deste debate no Movimento, é fundamental ouvir as crianças e saber delas como está a sua participação no MST e, em especial, nos instrumentos de comunicação infantil que foram criados para elas.

\section{NOTAS}

${ }^{1} \mathrm{O}$ presente texto é resultado do trabalho de monografia apresentada no curso de Especialização Trabalho, Educação e Movimentos Sociais através do Programa Nacional de Educação na Reforma Agrária (PRONERA), Escola Politécnica Joaquim Venâncio (EPSJV) e Escola Nacional Florestan Fernandes (ENFF).

${ }^{2}$ A pesquisa realizada para a monografia (2013) teve caráter documental. Foi realizada a partir do levantamento da produção do MST sobre, para e com a infância, considerando os relatórios, as cartilhas, os cadernos de educação, revistas, jornais, CDs e livros produzidos pelo MST. Destacamos que a maioria destes materiais consiste numa elaboração e produção coletiva. Após a obtenção dos materiais, eles formam submetidos a uma categorização para a sua organização. A categorização estabelecida a priori, teve como foco e objeto a relação com a infância, mais especificamente, se ela era ou não destinatária do documento. A distribuição das produções foi feita em três categorias e um recorte das produções de circulação internas. O conjunto do material contempla um volume de 42 títulos, distribuídos da seguinte forma: 7 títulos de produções sobre a infância; 15 títulos de produção para as crianças; 5 títulos de produção para e com as crianças; 15 documentos de circulação interna. A escolha que faço para esse artigo é de apresentar uma síntese sobre a infância dos Assentamentos e acampamentos e as 3 categorias de análise sobre os documentos que tratam da infância do MST.

${ }^{3}$ JST - Jornal Sem Terra, edição n³08, nov/dez 2010.

${ }^{4}$ Embora a significação social do termo creche tenha sido bastante modificada com a LDB de 1996, referindo-se ao atendimento educacional da criança de 0 a 3 anos de idade no sistema formal de ensino, o MST, na ocasião, preocupava-se com a marca histórica de classe presente nessa terminologia que imprimia um modelo que não atendia as necessidades educativas na formação da criança. Creche e pré-escola tiveram origens e destinações diferentes conforme a classe social da criança: creche originou-se para atender as trabalhadoras e a pobreza e pré-escola foi a terminologia e o modelo usados no atendimento das classes favorecidas. (MST, 2004, p.15).

${ }^{5}$ Fundo das Nações Unidas para a Infância - UNICEF.

${ }^{6}$ Documento Interno - A Infância Sem Terra: elementos para reflexão na Direção Nacional/ Outubro/2006 - São Paulo.

${ }^{7}$ São 13 cadernos de educação, sendo o primeiro intitulado Como fazer a escola que queremos, publicado em 1992 e a última edição, Dossiê MST e a Escola - Caderno n ${ }^{13}$, Edição especial, publicado em 2005.

${ }^{8}$ Inicialmente, este Congresso estava previsto para julho de 2013, porém foi adiado para fevereiro de 2014. 
${ }^{9}$ Todo o processo de preparação, discussão e edição foi realizado no Pontão de Cultura Rede Cultura da Terra, São Paulo/SP.

${ }^{10}$ As produções do concurso de redação e desenho, não foram categorizadas nessa pesquisa, por serem produções direcionadas para o trabalho com as escolas de assentamento e acampamentos.

11 A Via Campesina é um movimento Internacional, composto pelas várias organizações de camponeses, mulheres rurais, comunidades indígenas e negras da Ásia, África, America e Europa.

${ }^{12}$ Movimento Atingido pelas Barragens (MAB, Brasil).

${ }^{13}$ Movimento dos Pequenos Agricultores (MPA, Brasil).

${ }^{14}$ Movimento Nacional Campesino Indígena (MNCI, Argentina).

${ }^{15}$ União Nacional dos Camponeses (UNAC, Moçambique).

\section{REFERÊNCIAS}

ARAUJO, Edna Araújo. Essa Ciranda não é Minha só, ela é de todos nós: A educação das crianças Sem Terrinha no MST. (Dissertação em educação) UNICAMP, Campinas/SP 2009.

DEL PRIORE, Mary. História das crianças no Brasil. São Paulo: Contexto, 1999.

KRAMER, Sonia. A política do Pré escolar no Brasil. A arte do disfarce. $5^{\circ}$ edição. São Paulo, Ed. Cortez, 1995.

LOMBARDI, José Claudinei. Reflexões sobre Educação e Ensino na obra de Marx e Engels. (Tese em educação) UNICAMP, Campinas 2010.

MARTINS, José de Souza. O Massacre dos Inocentes. A criança Sem Infância no Brasil. São Paulo, ed. Hucitec, $2^{\circ}$ edição, 1993.

MOVIMENTO SEM TERRA. A Escola Itinerante Paulo Freire no $5^{\circ}$ Congresso. Coleção Fazendo Escola n ${ }^{\circ}$. Brasília, 2008.

Crianças em Movimento: As Mobilizações Infantis no MST. Coleção Fazendo

Escola ${ }^{\circ}$ 2. São Paulo, 1999.

$\mathrm{n}^{\circ} 12.2004$.

Educação Infantil. Movimento da vida, dança do aprender. Caderno de Educação

Educação da Infância Sem Terra. Orientação para o trabalho de base. Caderno a

Infância ${ }^{\circ} 1$. São Paulo, 2011.

PISTRAK, Moisey M. Fundamentos da Escola do Trabalho. São Paulo: Expressão Popular, $1^{\circ}$ edição, 2000.

SÁ- SILVA, Jackson Ronie. ALMEIDA, Cristóvão Domingos de. GUINDANI, Joel Felipe. Pesquisa documental: pistas teóricas e metodológicas. Revista Brasileira de História \& Ciências Sociais. Ano I - Número I - Julho de 2009. Disponível em: www.rbhcs.com

SILVA, Ana Paula Soares da; FELIPE, Eliana \& Márcia RAMOS. Infância do Campo. IN: CALDART, Roseli; PEREIRA, Isabel; ALENTEJANO, Paulo \& FRIGOTTO, Gaudêncio (orgs). Dicionário da Educação do Campo. Rio de Janeiro, São Paulo: Escola Politécnica de Saúde Joaquim Venâncio, Expressão Popular, 20012. 